\title{
ISSN: 2668-5728
}

\section{https://materials.international}

Materials

International

Volume 2, Issue 1, Page 048

2020

Advertisement, Call for papers

\section{Call for papers on special issue "Advances in additive manufacturing: modeling, design, and application"}

\section{Guest Editor}

Mohammad Elahinia 1,*(D), Mohammadreza Nematollahi 1,*(D), Nima Shamsaei 2,*(D)

1 Dynamic and Smart Systems Laboratory, Mechanical Industrial and Manufacturing Engineering Department, The University of Toledo, OH 43606, United States

2 National Center for Additive Manufacturing Excellence (NCAME), Auburn University, Auburn, AL 36849, United States

* Correspondence: melahinia@utoledo.edu; Scopus ID: $\underline{9638289200}$ mnemato@urockets.toledo.edu; Scopus ID: 57202372412 shamsaei@auburn.edu; Scopus ID: $\underline{57207585112}$

Aim \& Scope: Additive Manufacturing (AM) is revolutionizing the manufacturing industry. Building parts layer by layer makes fabrication of geometries which were impossible otherwise. Freedom of fabrication, rapid and low-cost prototyping, and reduction in material waste are only a few of advantages that AM offers to many industries from biomedical to aeronautics. Hence, AM is getting lots of interest over the past few years. These combined with lower cost of $3 \mathrm{~d}$ printers is making this pace even faster. To keep up with the advancements in AM, this special issue aims to publish high quality research articles in the field of additive manufacturing and its related topics. This includes but not limited to alloy design for $\mathrm{AM}$, new $\mathrm{AM}$ technologies and process optimization, processmicrostructure-property, characterization of AM parts, modeling AM processes, topology optimization, fatigue, fracture, and failure analysis, tailoring properties, and functionally graded materials through AM. New applications are welcome, as well.

We kindly invite you to submit a manuscript(s) for this Special Issue. Full papers, communications, and reviews are all welcome.

Keywords: Additive manufacturing; material science; characterization; implants; biomedical; design; optimization; modeling.

(C) 2020 by the author(s). This file is distributed under the terms and conditions of the Creative Commons Attribution (CC BY) license (http://creativecommons.org/licenses/by/4.0/).

\section{Subtopic}
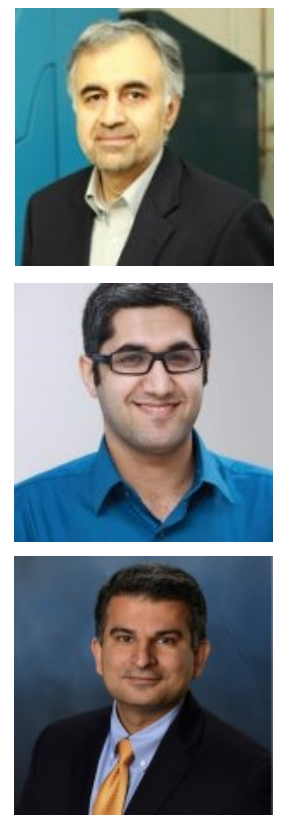

\footnotetext{
1 New materials and techniques for additive manufacturing

2 Process optimization; Characterization of additively manufactured parts

Modeling of AM processes; Design and topology optimization for AM

Emerging applications using AM techniques

5 Fatigue and failure of additively manufactured parts
}

Deadline for manuscript submissions: 31 December 2020

To submit your manuscript click here. To read author guidelines click here. 